\title{
Avoin tiede ajaa tiedeseurat pohtimaan rooliaan
}

\author{
$+y$ \\ Tiedejulkaisemisen globaali murros kohti avoimia \\ julkaisuympäristöjä pakottaa tiedeseurat arvioimaan \\ uudelleen toimintaansa ja tiedejulkaisemista.
}

VALMISTELLESSANI 1980-LUVUN PUOLIVÄLIN tietämillä kasvatustieteen pro gradu -tutkielmaa luovuudesta sain kokea, mitä tarkoittaa tiedon saavutettavuus. Käyttämässäni kirjallisuudessa viitattiin kiintoisilta vaikuttaviin julkaisuihin, mutta eipä niitä Joensuun yliopiston kirjastosta löytynyt. Tutkimusaihetta käsittelevää kirjallisuutta oli muutenkin hankala löytää. Oman kirjaston nimikkeitä piti hakea pahvikorteilta ja mikrofilmeiltä. Kansainvälisten julkaisujen etsinnässä olisi pitänyt turvautua paksuihin, pienellä präntillä painettuihin hakuteoksiin, bibliografioihin. Jätin ne käyttämättä.

Lopulta kokosin graduni saatavilla olevista aineksista. Tarvitsemani tekstit löysin käymällä kirjastossa järjestelmällisesti läpi kasvatustieteen, psykologian, sosiologian ja filosofian hyllyt. Yhden niteen kävin lainaamassa Helsingin yliopiston kirjastosta. Loppu- tuloksena oli eri tieteenalojen lähestymistapoja yhdistelevä kyhäelmä, joka julkaistiin sittemmin tiedekunnan julkaisusarjassa.

Ensimmäinen tutkimustyöni olisi jäänyt tekemättä, jos pääsyäni hyllyjen väliin olisi jollain tapaa rajoitettu. Kun valmistumisen jälkeen jatkoin opiskelujani, tein merkittävän havainnon: yliopiston kirjaston kokoelmissa oli melkoisia aukkoja. Tieteellinen tieto oli kuitenkin siinä mielessä avointa, että tarvitsemansa niteen tai artikkelin saattoi tilata kaukolainana.

Ensimmäistä kertaa törmäsin maksumuuriin: tieto oli kyllä kenen tahansa saatavilla, kunhan oli valmis maksamaan kaukolainamaksun. Artikkelien hinta oli todella suolainen. Mitä pidemmälle tutkimukselliset pyrintöni etenivät, sitä ilmeisempää oli, että Joensuussa oli hankala tehdä kansainvälisesti kiinnostavaa tutkimusta. Etenkin kirjastojen ulkomaisten tiedelehti- 


\section{TIEDON LEVIÄMISEN}

\section{ESTEEKSI TULI MAKSUMUURI.}

en kokoelmat olivat surkuteltavat, eikä tilanne aikaa myöten juurikaan parantunut.

Lisäksi tiedonkulkua vaikeutti keskeisten ulkomaisten lehtien siirtyminen kaupallisille kustantajille. Kehityskulku käynnistyi 1960-luvulla, ja vuonna 2013 peräti puolet kaikista tiedeartikkeleista ilmestyi viiden suurimman kustantamon hallinnoimissa lehdissä (Steinberg 2015; Larivière ym. 2015). Tieteen sisäinen logiikka pakotti yliopistot tilaamaan eri tieteenalojen keskeiset lehdet, minkä ansiosta vuosikertojen tilausmaksuja saattoi huoletta korottaa. Tiedon leviämisen esteeksi tuli käyttäjien maksukyky.

Samoihin aikoihin kun tiedelehtien kustantaminen keskittyi muutamalle kaupalliselle toimijalle, muuttuivat julkaisujen kokoamisen, julkaisukuntoon saattamisen ja levittämisen ratkaisut. Perinteisen järjestelmän painokoneineen ja lehtien postituksineen korvasi sähköinen julkaiseminen. Julkaisukulut romahtivat, mutta kirjaston maksamat tilaushinnat jatkoivat nousuaan. Tilanne on vinksahtanut, sillä vaikka tekstien kirjoittajat ja arvioitsijat eivät yleensä saa palkkaa tekemisistään ja vaikka tieteellinen tutkimus pyörii käytännössä julkisin varoin, suurta osaa maailmassa tuotetusta tieteellisestä tiedosta hallinnoi puolen tusinaa kaupallista kustantamoa. Paperiaikaan tämän voisi vielä ymmärtää. Sähköisen julkaisemisen aikakaudella järjestelystä on ollut lähinnä vain haittaa. (ks. Conley \& Wooders 2009.)

\section{TIETO KAUPPATAVARANA}

Kansainvälisen tiedekustantamisen kaupallistuminen näkyy myös suomalaisten kirjastojen hankintakuluissa. Jo paperiaikaan joidenkin tieteenalojen avainlehtien tilaushinnat olivat suolaisia, eikä sähköinen julkaiseminen tuonut helpotusta. Se kuitenkin mahdollisti lehtien myynnin tieteellisille kirjastoille satojen, jopa tuhansien nimikkeiden nipuissa.
Kun tuotteen valmistaminen ja jakelu on käytännössä ilmaista, myyntivoitto kasvaa väkisinkin huomattavaksi. Kansainväliselle lukijakunnalle suunnattujen tiedelehtien kustantajille voitto voi olla jopa 40 prosenttia liikevaihdosta (Larivière ym. 2015). Maksajina ovat yliopistot ja tutkimuslaitokset.

Vuonna 2016 suomalaisten tieteellisten kirjastojen ja tutkimuslaitosten on arvioitu kuluttavan tiedelehtien tilauksiin 23 miljoonaa euroa (Tiedote 2016). Lähes yhtä suuren summan Suomen Kulttuurirahasto jakoi apurahoina samana vuonna. Vuotta aiemmin yksin Itä-Suomen yliopisto maksoi reilut 567000 euroa siitä, että henkilökunta ja opiskelijat saivat käyttää Elsevierin tietokantoja. Vielä vuonna 2010 materiaalipaketin hinta oli kolmanneksen halvempi. (ATT-hanke 2017.)

Korkeita hintoja on vähätelty vetoamalla siihen, nipputilaukset ovat itse asiassa edullisia, sillä julkaisujen keskimääräinen hinta on pienempi kuin erillistilauksissa (Odlyzko 2013). Vaikka tarpeellisten julkaisujen rinnalla jaetaan kahmaloittain kylkiäisiä, tarpeellinen tuote ei muutu yhtään edullisemmaksi. Vaikka modernin tietotekniikan ansiosta on mahdollista jakaa tutkimustietoa reaaliaikaisesti kaikille tarvitseville, suuri osa tiedelehdissä julkaistusta tiedosta on kaikkea muuta kuin avointa (Beverrungen ym. 2012).

Yliopiston henkilökunnan jäsenenä kuulun siihen etuoikeutettujen joukkoon, jolla on lähes rajoittamaton pääsy tutkimustietoon. Kun on joutunut työskentelemään ympäristössä, jossa tutkimustiedon saavutettavuus on ollut heikkoa, osaa arvostaa tiedon demokratisointiin tähtääviä hankkeita. Sellainen oli vuonna 2012 käynnistynyt kapinaliike, jossa tutkijat ilmoittivat kieltäytyvänsä julkaisemasta ja toimimasta vertaisarvioijina Elsevierin hallinnoimissa tiedelehdissä (ks. Heyman ym. 2016). Tarkoitus oli estää tiedeyhteisön taloudellinen riisto.

Suomessa tieteentekijöiden kapinaliike on saanut vain vähän näkyvyyttä, eikä ihme. Vaikka esivalta kannustaa avoimeen julkaisemiseen, se suosii lehtiä, jotka ovat kaikkea muuta kuin avoimia ja kirjastoille hinnakkaita (Kansalliskirjasto 2015). Taustalla on pyrkimys nostaa suomalaisen tieteen vaikuttavuutta. Kun tiedetään, että yliopistojen rahoitusmallissa opiskelijan työllistyminen valmistumisen jälkeen on 
arvioitu yhden prosentin arvoiseksi ja julkaiseminen 13 prosentin arvoiseksi, ei ole vaikea arvata, mitä vaikuttavuudella tarkoitetaan.

Yksikään kotimainen kasvatusalan lehti ei yllä arvostetuimpien lehtien joukkoon. Kansainvälisiä tiedelehtiä julkaisevien kaupallisten kustantajien asema säilyy siten tulevaisuudessakin vahvana.

Julkisin varoin tuotetun tiedon piilottamisesta maksumuurien taakse kärsivät niin veronmaksajat kuin tiedekin. Lisäksi on tutkijan edun mukaista, että artikkeli saa mahdollisimman laajan lukijakunnan. Digiaikana tiedejulkaiseminen ei enää tarvitse kaupallisten kustantamojen vetoapua.

\section{VAPAA TIEDE?}

Vapaat tietokannat tarjoavat tutkimustiedon varannon, jollaisesta muutama vuosi sitten ei voinut edes uneksia. Lääke- ja terveystieteen julkaisuihin painottuva PubMed kattaa kymmeniä miljoonia alan julkaisuja. DOAJ on taas open access -julkaisujen yhteisalusta, jossa on edustettuna reilut yhdeksän tuhatta tiedelehteä ja lähes kaksi ja puoli miljoonaa artikkelia. Toisin kuin kaupalliset tietokannat, joita voivat käyttää lähinnä korkeakoulujen henkilökunta ja opiskelijat, Pubmed ja DOAJ ovat kaikille avoimia.

Tietoliikenneyhteyksien nopea kehitys on alusta pitäen rakentunut avoimen tiedon ja jaetun osaamisen periaatteille, joten avoimet tietokannat ovat erottamaton osa modernia digiaikaa. Ohjelmistopuolella osaamisen jakamisesta ovat esimerkkeinä Linuxiin perustuvat tietokoneiden käyttöjärjestelmät, Libre Office-toimisto-ohjelmapaketti ja lukuisat muut verkosta vapaasti imuroitavat sovellukset.

Avointen tietokantojen louhintaan tarkoitettu Open Knowledge Map -hakuohjelma antaa hakutuloksen myös kuvana. Se työstää hakutuloksensa tietovarannosta, jossa on yli sata miljoonaa julkaisua. Niistä kuutisenkymmentä prosenttia on alkuaankin open access -artikkeleita (Kraker ym. 2016). Tietovarantoon pääsee kuka tahansa käsiksi mistä päin maailmaa tahansa.

Digitalisoitunutta maailmaa voi hahmottaa vain, jos ymmärtää, että sen liikkeelle paneva voima on tiedon ja osaamisen avoimuus. On mahdollista, että uuden tekniikan myötä tiedon leviämisen esteet poistuvat, tieteentekijäkollektiivien pyörittämästä open access -julkaisemisesta tulee vallitseva käytäntö ja tutkimustieto avautuu kaikille (ks. van Noorden 2013). Samalla paperijulkaisut korvautuvat verkkolehdillä, sillä vain sähköinen julkaiseminen mahdollistaa laajimman mahdollisen jakelun pienimmillä mahdollisilla kustannuksilla.

Tieteen vapaus muistuttaa luonnonvoimaa, jonka vaikutusta voi vain pakkokeinoin rajoittaa. Moderni tietotekniikka on vapauttanut tieteen paperijulkaisemisen rajoituksista, mutta aiempina vuosikymmeninä muodostuneet rakenteet hidastavat tiedejulkaisemisen avautumista. Suomessa kehityksen pahin jarru on opetus- ja kulttuuriministeriö (OKM), joka mittaa tieteenteon laatua arvostetuimmissa tiedelehdissä julkaistujen artikkelien lukumäärällä (OKM 2017). Ne ovat lähes poikkeuksetta kaupallisten kustantamojen hallinnassa.

Artikkelin arvon määrittäminen julkaisufoorumin perusteella merkitsee paluuta esidigitaaliseen aikaan. Julkaisukäytänteiden muutos ja ennen kaikkea open access -julkaiseminen heijastuvat samalla artikkelien arviointijärjestelmään.

\section{ARVOKKAAN TUTKIMUKSEN TUNNISTAMINEN}

Tiedetekstin arvo voidaan määrittää kahdella tapaa: ennen artikkelin julkaisemista tai julkaisemisen jälkeen. Nykyään vallitsevana on vertaisarviointiin perustuva järjestelmä, jossa tekstistä pyydetään etukäteen kahden ja joissakin lehdissä jopa kolmen aihepiiriä tuntevan tieteentekijän lausunnot.

Tiedejulkaisemisessa vertaisarviointi on varsin tuore käytäntö. Aina 1900-luvun puoliväliin saakka artikkelitarjokkaiden arvioinnista huolehtivat tiedelehden päätoimittaja ja erikseen nimetty toimituskunta (Burnham 1990; Spier 2002). Käytänteen muistona monessa tiedelehdessä esitellään yhä pitkä lista toimituskuntalaisia. Vertaisarviointi oli tarpeen julkaisuympäristössä, jossa huolimattomasti tai kerrassaan vilpillisesti toteutettua tutkimusartikkelia oli mahdotonta jälkikäteen poistaa lehden sivuilta. Voitiin vain julkaista ilmoitus, jossa pahoiteltiin toimituksen erhettä. 


\section{SUURIN OSA IHMISKUNNAN}

HISTORIASTA ON

TALLENNETTU

PAPERIMUODOSSA.

Vertaisarvioinnin ohella tutkimuksen laadun mittarina on pidetty julkaisualustaa. Suomessa on käytössä kolmiportainen Julkaisufoorumin jufo-luokitus, jonka mukaisesti asiantuntijapaneelit sijoittavat lehtiä neljään tasoon:

$\mathbf{0}$ ei-tieteelliset julkaisut

1 perustaso

2 johtava taso

3 korkein taso

Arviointi perustuu ajatukseen, että jotkin lehdet ovat laadukkaampia kuin jotkut toiset.

Lehtien asettaminen arvojärjestykseen oli mielekästä aikana, jolloin korkeakoulut joutuivat resurssipulassa päättämään, mitkä julkaisut kirjaston valikoimasta oli välttämättä löydyttävä. Nykyään artikkeleita poimitaan sähköisistä tietokannoista hakusanojen avulla, eikä tulosjoukko erottele osumia lehtien mukaan, ellei niin erityisesti haluta.

Miten enää voi erottaa jyvät akanoista? Yksi vaihtoehto on jufo-luokitukseen perustuva järjestelmä, jolla tulosjoukko asetetaan arvojärjestykseen. Tiedelehtien kenttä on kuitenkin jatkuvassa liikkeessä: uusia lehtiä syntyy ja vanhoja hiipuu. Siksi tiedetekstien laadunvalvonnassa siirrytään todennäköisesti asteittain etukäteisarvioinnista jälkikäteisarviointiin. Näin syntyy järjestelmä, jossa tekstin tieteellinen merkitys ei määrity julkaisualustan vaan käyttäjien arviointien pohjalta. On esimerkiksi ehdotettu, että arvioinnin voisi toteuttaa samaan tapaan kuin tieteentekijöiden verkkoyhteisössä, Academia.edussa (ks. Kansalliskirjasto 2015), jossa voi jakaa omia tutkielmiaan ja arvioida muiden tekstejä. Ajatus on mielenkiintoinen, vaikka Academia.edu ei ole erityisen hyvä esimerkki vapaasta tieteestä.

\section{TIEDESEURA JA MUUTTUNUT JULKISUUS}

Tiedejulkaiseminen ja tutkimustiedon käytön muutos heijastuu väistämättä tiedeseurojen arkeen. Vielä muutama kymmenen vuotta sitten tiedelehden kustantaminen oli olennainen osa tiedeseurojen toimintaa. Paperijulkaisun kokoaminen, painattaminen ja jakelu vaativat kuitenkin paljon työtä, minkä vuoksi moni seura on ulkoistanut lehtensä teknisen toteutuksen - muualla maailmassa usein kaupalliselle kustantajalle. Molemmat sopijapuolet hyötyvät järjestelystä: tiedeseura saa pysyvän tulonlähteen ja kustantamo tuotteen, joka myy itse itsensä.

Sen sijaan tieteentekijää ja tiedeyhteisöä järjestely ei palvele. Tekstin jääminen maksumuurin taakse tai hakukoneiden saavuttamattomiin vaikeuttaa tutkimustiedon leviämistä, osin jopa estää sen. Tieteellinen tieto on avointa vain niissä teollistuneiden maiden yliopistoissa, joissa raha ei ole ongelma. Niidenkin lukumäärä näyttää tosin vähenevän nopeasti (Sample 2012).

Suomenkielisen tutkimuksen leviämistä ei vaikeuta niinkään kustantajien ahneus kuin tiedeseuratoiminnan käytänteet. Oma lehti on perinteisesti ollut jäsenhankinnan houkutin, säännöllisin väliajoin kotiin tupsahtanut tietopaketti alan tuoreimmasta tutkimuksesta. Nykyään suuri osa suomalaisestakin kasvatusalan tutkimuksesta julkaistaan kansainvälisillä foorumeilla, joten jäsenedun houkutinarvo on vähenemässä. Ja vaikka järjestely vielä näyttäisikin toimivan, tiedeseuran ensisijainen tehtävä on levittää oman tieteenalansa tutkimustuloksia mahdollisimman nopeasti mahdollisimman laajalle.

Jos tiedelehteä ei voi enää käyttää jäsenhankinnan houkuttimena, voisiko tilalle tarjota jotain muuta? Esimerkiksi Aikuiskasvatusta kustantavan Aikuiskasvatuksen Tutkimusseuran säännöissä todetaan, että yhdistyksen tarkoituksena on tukea ja edistää aikuiskasvatustyötä. Tiedejulkaiseminen palvelee hyvin perustehtävää, mutta tutkimus- ja selvitystyö on vain yksi osa seuran toimintaa. Säännöissä nimittäin luvataan edistää toimijoiden välistä tiedonkulkua ja kehittää alan koulutusta. Se onnistuu parhaiten järjestämällä tapahtumia, joissa tutkijat ja alan toimijat voivat kohdata toisiaan ja joissa on tarjolla ajankohtaista tietoa 
aikuiskasvatuksesta ja alaa koskevaa koulutusta. Tapahtumaan osallistuminen voisi olla jäsenille selvästi muita edullisempaa. Itse asiassa tällainen tapahtuma on jo olemassa, nimittäin Aikuiskasvatuksen tutkimuspäivät.

\section{TARVITAANKO ENÄÄ PAPERILEHTEÄ?}

Tiedeteksteissä verkkojulkaiseminen on vallitseva käytäntö. Hakukoneiden käyttö tutkimuskirjallisuuden etsinnässä vähentää julkaisualustojen merkitystä. Onko printtilehdelle enää lainkaan tarvetta?

Tiedon säilyvyyden kannalta on. Arkistoitu digitaalinen aineisto voi tuhoutua yhtä helposti kuin paperiaineistot. Itse asiassa jopa helpommin, sillä perinteisen kirjaston palaminen vie oman aikansa, kun taas sähköisen kirjaston voi tuhota painamalla delete-nappia.

Oma ongelmansa on aineiston tallennusmuoto. Tiedostoja on voitava lukea vielä kymmenien, jopa satojen vuosien kuluttua. Paperijulkaisemisessa käytettävyyden ja säilyvyyden ongelma on ratkaistu käyttämällä arkistointikelpoista paperia ja painomustetta. Suurin osa ihmiskunnan historiasta on tallennettu paperimuodossa, ja käytäntö on osoittautunut toimivaksi. Joissakin kaikille avoimissa, open access -verkkolehdissä on käytössä hybridimalli, jossa lehti on saatavilla verkossa mutta sillä tavoin taitettuna, että sen voi helposti tulostaa paperimuotoon. Tiedostojen lukukelpoisuutta suojellaan käyttämällä avoimen koodin ohjelmia: kun koodi tunnetaan, tiedostoja voi lukea ongelmitta.
Vaikka tekstit voisikin lukea suoraan tietokoneen ruudulta tai mobiilisti, paperille painettu tiedelehti on yhä edelleen verraton käyttöliittymä. Tiedon avoimuuden periaate kuitenkin edellyttää, että tiedeartikkelit julkaistaan sähköisesti ja open access -muodossa. Siksi perinteistä tiedelehtiformaattia on arvioitava uudelleen.

Kuulun viiteen tiedeseuraan, joista neljässä jäsenmaksuun sisältyy seuran oma lehti. Jokaisen lehden vuosikerta on satoja sivuja, ja jonnekin ne pitäisi saada säilöttyä. Pääosa lehtien sisällöstä on tiedeartikkeleita, joilla on monesti vain vähän tekemistä omien tutkimusintressieni kanssa. Tosin on lehdissä aina myös yleisestikin kiinnostavia kirjoituksia, kuten katsauksia ja kirjaesittelyjä. Oma suosikkini tiedelehtien joukossa on Tieteellisten seurain valtuuskunnan (TSV) kustantama Tieteessä tapahtuu, joka on paras tiedettä popularisoiva julkaisu Suomessa. Sen haluan saada luettavakseni paperiversiona, ja melkeinpä aina se tulee luettua kannesta kanteen.

Mutta olisiko aikuiskasvatustieteen piirissä tarvetta myös paperijulkaisulle? Tieteenala ja seuran tarkoituksen näkökulmasta näin pitäisi olla. Tiedeseuran julkaiseman lehden pitäisi kuitenkin olla kuin myyntiesite, jonka avulla lukija voi tutustua aikuiskasvatuksen eri muotoihin, alaa koskevaan tutkimukseen ja seuran toimintaan. Paperilehden kohderyhmänä olisivat tieteentekijöiden ja aikuiskasvatuksen parissa työskentelevien lisäksi kaikki ne, joiden on hyvä tietää, mitä aikuiskasvatus on ja mihin sitä tarvitaan. Yleiskatsauksellisuus olisi piristävä poikkeus aikana, jolloin tieto ja tutkimus ovat aina vain pirstaleisempia.

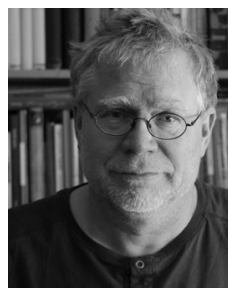

RISTO IKONEN

$\mathrm{KT}$, yliopistonlehtori

Itä-Suomen yliopisto 
ATT-hanke (2017). Avoin tiede ja tutkimus -hanke. Kustantajahintatiedot Suomessa 2010-2015. Opetus- ja kulttuuriministeriö. https:// etsin.avointiede.fi/fi/dataset/urn-nbn-fi-csckata20160609092300369981. (3.4.2017)

Beverungen, A., Böhm, S. \& Land, C. (2012). The poverty of journal publishing. Organization 19 (6), 929-938.

Burnham, J. C. (1990). The Evolution of Editorial Peer Review. JAMA 263(10), 1323-1329.

Conley, J. P. \& Wooders, M. 2009. But what have you done for me lately? Commercial Publishing, Scholarly Communication, and Open-Access. Economic Analysis \& Policy 39 (1), 71-87.

Heyman, T., Moors, P. \& Storms, G. (2016). On the Cost of Knowledge: Evaluating the Boycott against Elsevier. Frontiers in Research Metrics and Analytics 1 (7). doi:10.3389/frma.2016.00007.

Kansalliskirjasto (2015). Teema: Tiedon ja tieteen saatavuuden tulevaisuus. Kansalliskirjasto 2/2015. https://issuu.com/kansalliskirjasto/docs/netti_kk_22015_uusi.

Kraker, P., Kittel, C. \& Enkhbayar, A. 2016. Open Knowledge Maps: Creating a Visual Interface to the World's Scientific Knowledge Based on Natural Language Processing. 027.7 Zeitschrift für Bibliothekskultur; Journal for Library Culture 4 (2), 98-103. http://0277.ch/ojs/index.php/cdrs_0277/ article/view/157/355.

Larivière V., Haustein, S. \& Mongeon, P. (2015). The Oligopoly of Academic Publishers in the Digital Era. PLOS ONE 10(6). http://journals.plos.org/plosone/ article? id=10.1371/journal. pone.0127502.
Odlyzko, A. 2013. Open access, library and publisher competition, and the evolution of general commerce. Evaluation Review 39(1), 130-163.

OKM (2017). Korkeakoulutuksen ja tutkimuksen tilastot. Opetus- ja kulttuuriministeriö, korkeakouluja tiedepolitiikan osasto, strategisen ohjauksen vastuualue. http://minedu.fi/korkeakoulu-jatutkimustilastot. (4.4.2017)

Sample, I. (2012). Harvard University says it can't afford journal publishers' prices. The Guardian, 24.4.2012. https://www.theguardian.com/science/2012/apr/24/ harvard-university-journal-publishers-prices.

Spier, R. (2002). The history of the peer-review process. TRENDS in Biotechnology, 20 (8), 357-358.

Steinberg, P. (2015). Reclaiming Society Publishing. Publications 3 (3), 150-154. doi:10.3390/ publications3030150.

Tiedote (2016). Avoimiin julkaisumalleihin siirryttävä ripeästi. Kansalliskirjasto. Verkkotiedote 26.4.2016. https://www.kansalliskirjasto.fi/fi/uutiset/avoimiinjulkaisumalleihin-siirryttava-ripeasti.

van Noorden, R. (2013). Open access: The true cost of science publishing. Nature 495 (7442), 426-429. http://www.nature.com/news/open-access-the-truecost-of-science-publishing-1.12676 (9.4.2017) 